\section{Contractarianism Gone Wild: Carruthers and the Moral Status of Animals}

\author{
David Boonin-Vail \\ Tulane University
}

Editor's Note: This paper by Professor Boonin-Vail, comments by Professor Robinson, and Boonin-Vail's reply to those comments were presented at the Eastern Division meetings of the Society for the Study of Ethics and Animals, held in Atlanta, Georgia, December, 1993.
In his recent contribution to the literature on the moral status of animals, Peter Carruthers argues that "some version of contractualism provides us with the most acceptable framework for moral theory," and he defends two central claims about such a theory: that it provides "a theoretical framework that accords full moral standing to all human beings, while non-arbitrarily withholding such standing from animals," and that it can account for many common-sense beliefs about the treatment of animals, while at the same time providing "no support for those who would wish to extend still further the moral protection already available" to them.

I am not concerned here to question the merits either of contractarian ${ }^{2}$ moral theory in general, or of Carruthers' version of it in particular. Instead, I want to grant the acceptability of such a theory for the sake of the argument, and to challenge Carruthers' two crucial claims about it. First, I will argue that if moral contractarianism provides support for common-sense restrictions on our treatment of animals for the sorts of reasons that Carruthers develops, then it provides support for extending moral protection substantially beyond the level currently available to them; I will argue, in particular, that if Carruthers' arguments are

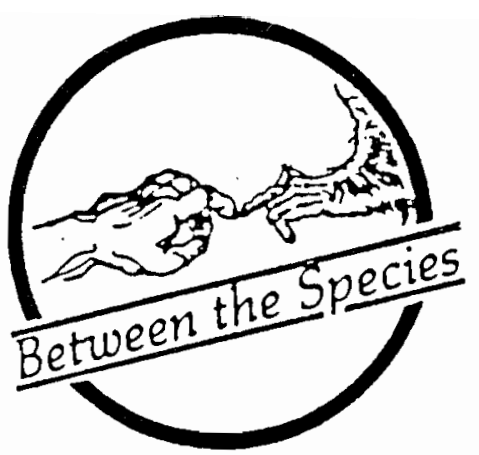

successful, they also provide a contractarian justification for morally criticizing the practice of factory farming, though this is meant merely as one example. Second, without attempting to settle the question of precisely which additional restrictions on our treatment of animals such contractarian arguments might ultimately be used to underwrite, I will argue that whatever principles are finally agreed to, they involve attributing to animals a moral standing that is just as "full" as the moral status such arguments accord to some humans.

I.

A contractualist moral theory, as Carruthers uses the term, is one which "views morality as the result of an imaginary contract between rational agents, who are agreeing upon rules to govern their subsequent behavior," and which attempts "to justify a system of moral principles by showing that they would be agreed upon by rational agents in certain ideal circumstances" (pp. 35-36). The best-known version of such a theory remains that of John Rawls, in which the ideal circumstances requisite for ensuring impartiality are generated by endowing rational agents with general knowledge of the social sciences and then placing them behind a "veil of ignorance" which keeps them from knowing facts about their particular characteristics and circumstances. Rawls is himself primarily concerned to apply this method to the problem

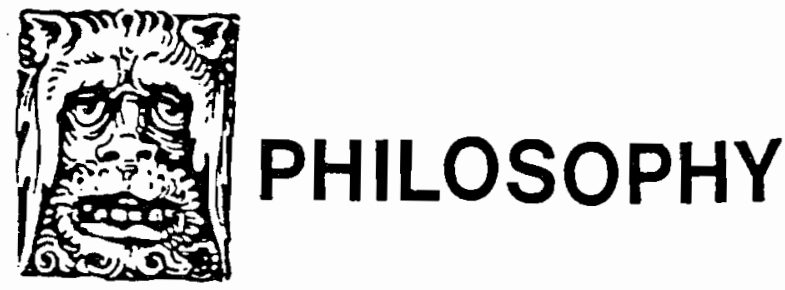


of political justice, but Carruthers rightly notes that it can be extended to provide a general theory of morality: morality consists of those rules governing human conduct which would be agreed to by agents placed in such ideal circumstances. ${ }^{3}$

Carruthers expresses some concern that contractualist moral theory not be identified exclusively with its Rawlsian version, and so notes that on the view developed by Thomas Scanlon, the agents involved are allowed the sort of knowledge of their particular situation which is ruled out in Rawls' version. The account of morality, on this view, is that "moral rules are those that no one could reasonably reject as a basis for free, unforced, general agreement amongst people who share the aim of reaching such an agreement" (p. 38). But Carruthers suggests that the idealizations exploited by Scanlon achieve the same effect as Rawls' veil of ignorance, ${ }^{4}$ and he continues to employ this Rawlsian device in his own discussions of contractualism in general. I will follow Carruthers, then, in characterizing the contractarian theory of morality as one on which the rules of morality are those which would be selected by rational agents from behind a veil of ignorance. And I want to follow Carruthers in asking two questions: what is the content of the principles regulating our treatment of animals which would be agreed to under such conditions? And how does the moral status which is conferred to animals by the acceptance of such principles differ from the moral status which is conferred on some humans by the acceptance of principles regulating our treatment of them?

\section{II.}

Carruthers develops two distinct arguments to show that rational agents choosing principles of conduct from behind a veil of ignorance would accept some restrictions on their treatment of animals. This is important, on Carruthers' account, because if it could be shown that such agents would embrace a code of behavior which imposed no limits at all on their treatment of animals, this would likely be taken as too strongly counterintuitive to allow the theory as a whole to achieve a position of reflective equilibrium. It is possible, of course, that Carruthers' two arguments ${ }^{5}$ for the acceptance of such restrictions will be found to be unconvincing, and that his defense of contractarianism will be rejected as implausible for that very reason. I will not offer any defense of his arguments here, but will instead argue that if they are accepted, then, contrary to Carruthers, there is no good reason to prevent them from being used to justify moral restrictions on our treatment of animals which go substantially beyond those which are presently accepted.

Carruthers' first argument concerns the great distress which causing an animal to suffer in turn causes to those humans who care deeply about the well-being of animals. Causing such distress by causing an animal to suffer for trivial reasons, Carruthers says, "would violate the right of animal lovers to have their concerns respected and taken seriously" (p. 107). And since wellinformed rational agents can expect that there will be many people who will have such concerns, "this may place on us an obligation not to cause suffering to animals, except for powerful reasons" (p. 106). Although Carruthers does not put it in this way, the point might best be understood as follows: as a rational agent behind a veil of ignorance, I do not know whether I will be one of those people who don't mind kicking a dog for trivial reasons or one of those who are deeply grieved by seeing another doing so. But because I expect the loss to me from such actions being morally permitted if I turn out to be a dog-lover to be greater than the gain to me if I prove to be a dog-hater, I do best by agreeing to a principle which would morally condemn a person for kicking a dog for trivial reasons. Reasoning under conditions of uncertainty, that is, I must choose the outcome with the best worse-case results, and it will be better to be a slightly inconvenienced dog-hater than a deeply-distressed dog-lover. ${ }^{6}$

Carruthers takes it that such an argument succeeds in equipping contractarianism with the ability to accommodate some of our common-sense views about the treatment of animals. But he insists that the argument, if accepted, cannot be extended to criticize such practices as painful methods of factory farming or of testing new commercial products on animals "even granting that the purposes subserved by such activities (cheaper meat, and new varieties of shampoo) are trivial." And his reason for this is that the constraints generated by this argument "would only apply to suffering that occurs in a manner that is unavoidably public":

For it seems that one can legitimately reply to those who complain of such activities [e.g., factory farming] in exactly the way that one would reply to those who are distressed by 
unusual sexual practices, for example. One can say: 'If it upsets you, don't think about it.' While granting that an unusual sexual practice (or the suffering of an animal) should not be flaunted in public, because of the offence this may occasion, it seems there can be no objection to it occurring in private (p. 107).

Now on many views of morality, it is indeed perfectly legitimate to reply to people who are distressed by the thought of what others do in the privacy of their own homes simply by saying, "if it upsets you, don't think about it." But the question is whether this can be a legitimate reply on the sort of contractarian account which Carruthers seems to envision. And it seems that it cannot. If people do think about it, and if thinking about it does upset them, then the fact of their distress is just as good a reason not to harm the animal in private as it was a reason not to harm it in public (after all, even in the case of witnessing a public beating, one could be admonished not to think about it). Indeed, it is the very same reason: choosing rules of conduct from behind a veil of ignorance, I do not know if I will be a person who gains some marginal advantage by producing meat sauce instead of tomato sauce or one who finds that she cannot avoid thinking about the great suffering animals must endure to provide such trivial benefits and who is greatly distressed as a result. In the absence of such knowledge, I decline to risk the greater cost, which is the serious distress rather than the trivial benefit, and so agree to a rule which would condemn the causing of such suffering in private as well as public places.

This analysis of the case of causing an animal to suffer away from the public view also reveals the crucial disanalogy between the examples of animal suffering and nonstandard sexual practices, a disanalogy which Carruthers overlooks entirely. Consider, for example, the question of whether private homosexual intercourse should be morally condemned. From behind the veil of ignorance, I do not know if I will be a homosexual or a person who is disturbed by the knowledge that other people engage in homosexual intercourse in the privacy of their own homes. Again, from the contractarian perspective, I cannot simply tell myself that if I am the latter sort of person I should simply be told to stop thinking about it, because such a person does think about it and does find himself distressed as a result. So the cost which will be imposed on me if I find myself the sort of person who has such thoughts must be taken into account in my deliberations from behind the veil of ignorance. But in this case, surely, the cost to me will be far greater if I turn out to be a homosexual who finds himself prohibited from pursuing sexual fulfillment, and so from behind the veil of ignorance, I will agree to accept principles which deem private homosexual intercourse to be morally unobjectionable. In both cases, then, the contractarian cannot simply ignore the costs to those who find themselves distressed by their thoughts of what others are permitted to do in private, nor can the weight of those costs justifiably be discounted. Sometimes they will be greater than the benefits to others and sometimes not, and so the restrictions which are grounded in the distress caused in this manner will have to be assessed by the contracting agents on a case by case basis.

Now two objections might be raised at this point. One is that in attempting to sever the case of homosexuality from the case of factory farming, I have underestimated how deeply disturbed many people will be by the thought that others are morally permitted to engage in homosexual intercourse in the privacy of their own homes. Perhaps their stress will be so great as to outweigh the cost to homosexuals of prohibiting their pursuit of sexual fulfillment. The other is that, even if I am right in this particular case, there will still be many other instances of private behavior in which the trivial benefits to the participants will be less than the cost in distress to those who disapprove, so that we will have to accept moral restrictions on many forms of private behavior typically thought to be morally unobjectionable. But these considerations, if established, would show only that a contractarian of the sort Carruthers has in mind would be forced to conclude that such forms of behavior are immoral. This might count as an objection to this sort of contractarianism itself, but it does nothir $g$ to undermine the claim that this is how such a contractarian should weigh the costs of distress in determining which rules would be chosen by rational agents deliberating from behind a veil of ignorance. It may well be that there are compelling reasons not to accept as moral the rules which agents would choose in such circumstances. My claim here has simply been that if we allow such agents to consider the distress caused to individuals by their knowledge of public harm to animals caused for trivial reasons, then there is no good reason to prevent them from considering the distress caused to those who find themselves upset by their knowledge that similar harms 
are allowed to be inflicted on animals in private. The distress caused to those concerned about the pains inflicted on animals in factory farming is great and the benefits to those who benefit trivial, ${ }^{7}$ so if Carruthers' argument from distress provides a reason to suppose that rational agents behind a veil of ignorance would accept any restrictions on their treatment of animals at all, then it also provides a reason, and an equally convincing reason, to suppose that they would agree to condemn factory farming. ${ }^{8}$

\section{III.}

Carruthers' second argument for the claim that rational agents behind a veil of ignorance would accept restrictions on their treatment of animals rests on the importance that such agents would attach to the development of good character. Since people often act from general dispositions and not strictly from deliberate adherence to explicitly formulated principles, Carruthers argues, such agents would agree not only to endorse the merits of certain rules of conduct, but also to encourage the development of those dispositions and traits of character which would best ensure compliance with them. In particular, he urges, such agents would likely agree to accept not only duties of non-interference with others, but also duties of assistance, and the most reasonable account of such duties would require each person "to develop a general disposition to help those in need, to be exercised when the opportunity arises to do so at no comparable cost to themselves." They would agree, in other words, to develop "a general attachment to the good of others" (p. 152), which would in turn commit them to trying "to develop a ready sympathy for one another's suffering" (p. 154).

And this in turn, Carruthers argues, would provide the basis for condemning acts which cause suffering to animals for trivial reasons (or for no reason at all or for their own sake). "Such actions," he argues, "are wrong because they are cruel. They betray an indifference to suffering that may manifest itself... in that person's dealings with other rational agents" (pp. 153-54). ${ }^{9}$ This is not to say that the contracting agents would want the people themselves to believe that the reason for acting kindly toward animals was that this was an effective way of improving their prospects for acting kindly toward other humans. The people being praised would have a direct sympathetic response to the suffering of animals, and the people being criticized would not. But the agents doing the evaluating from behind the veil of ignorance would criticize the absence of sympathy for animals on the grounds that it represented a potential threat to other people. So the contractarian may have a way to justify restrictions on our treatment of animals that is independent of appeals to the distress such actions may cause in animal lovers.

As with Carruthers' first argument, I am again concerned not to assess the merits of the argument itself, but to ask whether, if it is admitted, there are any good reasons to refuse to extend it beyond the limited restrictions on our treatment of animals which are already generally accepted, and in particular whether there are reasons not to extend it to a moral criticism of factory farming. Carruthers maintains that this argument, like the previous one, cannot be so extended, again granting that the social benefits of factory farming are themselves trivial. His reason is this: whether or not an act displays a defect of character depends on the circumstances and the motive from which it is performed. It is only when a person causes an animal to suffer for trivial reasons that he reveals a lack of sympathy that will be worrisome to the imagined rational contractors. And in the case of people who inflict pain on animals in their work on a factory farm, "the motives from which the people in question are acting are by no means trivial, since they are earning a livelihood."

There is thus no scope, here, for criticising the overall practices of factory farming and animal experimentation... This point is important because even if the reasons why we have such practices are trivial-cheaper meat and new varieties of cosmetics-the motives of those who engage in them are not. There is then no reason to claim that those people are cruel in what they do (pp. 159-60).

There are two problems with this response. One is that it seriously misrepresents the character from which the worker on the factory farm acts. To point out that such people earn a living at what they do suggests that they act from the motive of earning a living, as if they are faced with the choice of causing suffering to animals for trivial social benefits and earning a living, or not causing suffering to animals for trivial social benefits and earning no living at all. This impression is reinforced in the context of another argument, when 
Carruthers writes that it is "too much to demand that people should forgo employment out of respect for the feelings of animal lovers" (p. 167). But the choice is typically not between earning a living and not earning a living, but between different ways of earning a living. And given the existence of jobs with roughly comparable demands and compensations, a preference for the job which causes pain to animals for trivial social benefits is itself trivial, and the motive from which one acts in choosing to indulge such a preference is truly indifferent to the suffering of animals. ${ }^{10}$

Now it may at this point be objected that in the real world, workers do not always have their choice of occupations and that a person may well be faced with the choice of taking a job that requires him to harm animals for trivial social benefits and taking no job at all. And surely in such cases, he acts from a nontrivial motive in accepting such a job. But the question which the rational contractors behind the veil of ignorance must face is precisely whether it would be best that this be the sort of world in which they live. They must decide, that is, whether the pool of jobs from which it will be considered morally permissible to compete should include some jobs which involve causing suffering to animals for trivial social gains. Suppose most people who presently work for factory farms are simply motivated by a desire to earn a living. ${ }^{11}$ Then they will be equally satisfied if the agents choose a moral system which demands that the resources currently dedicated to factory farms should instead be allocated to creating other jobs which do not inflict pain on animals for trivial social purposes. But suppose there are a few who are motivated not by the desire to earn a living, but by the desire to earn a living specifically by inflicting serious harms on animals for trivial social gains. They, and only they, would be disappointed by the absence of such jobs. But their motive, unlike the motive of those who simply want to earn a living, is a cruel one, one which betrays an indifference to the suffering of animals. And so if Carruthers is right that contracting agents behind a veil of ignorance will want to minimize the flourishing of such motives, they will choose a moral system which condernns allowing resources to be allocated for the creation of the sorts of jobs which could only be preferred by those with such motives. So if the concern about character which Carruthers identifies is sufficient to justify condemning those who harm animals from trivial motives, then it will be sufficient to justify agreeing to the moral superiority of an economy in which people do not compete for jobs which cause pain to animals for trivial social benefits.

The second problem with Carruthers' attempt to rescue factory farming from the implications of his character-based argument is that he nowhere considers the character of the people who buy and consume the meat which makes the factory farm jobs possible. But even if it is plausible to claim that the workers who harm the animals act from nontrivial motives, it is not plausible to claim that this is so of the consumers who ultimately pay their salaries. The person who indulges in a preference for meat lasagna instead of vegetable lasagna does not act from the nontrivial motive of eating rather than not eating, but from the trivial motive of gaining an incremental increase in pleasure or convenience. Unless he finds himself in extremely unusual circumstances, in which factory-farmed meat offers the only prospects for nourishment, the consumer of the factory farm's products clearly acts from a motive which is indifferent to the pain of animals..$^{2}$ And so again, if Carruthers is right that contracting agents behind the veil of ignorance would condemn behavior which issues from such motives, then they would agree to condemn those who purchase and eat factory-farmed meat. And so even if such agents did not decide, as my first objection suggested, to condemn the allocation of resources to creating such meat-producing jobs in the first place, they would still agree to endorse a set of moral dispositions which would have the effect of leaving the factory farm industry to wither away.

Now it might be objected to this last argument that the consumer, unlike the factory-farm worker, betrays no indifference to the pain of the animals if he does not stand by and idly watch as the animals attempt to escape or listen unaffected to their cries of pain. But if the customer is truly not so indiffere - to their suffering, and so would be unwilling himself to participate in or bear witness to such painful practices being carried out simply for the sake of producing a slightly tastier meal, then his purchase of the end result still betrays an indifferent character. He is like the man who cannot bring himself to murder his estranged wife but who can with peace of mind hire someone else to do it for him. This is not to suggest, of course, that on the contractarian account of morality hiring a hit man is to be equated with ordering chicken McNuggets. It is simply to say that the relationship between doing something that betrays an unacceptable character and paying to hive 
someone else do it for you must be viewed as the same in both cases. The contractarian will presumably want to condemn the lack of sympathy of the person who hires the hit man, even if the person is himself too sensitive to inflict the harm himself. And so if Carruthers is right to claim that contracting agents will criticize people who cause pain to animals for trivial reasons, then such agents will also have reason to criticize those who enjoy the trivial benefits while paying others to inflict the requisite pain. If the character-based argument suffices to accommodate the common-sense views which Carruthers wishes to accommodate, then it must also underwrite a moral criticism of factory farming.

Carruthers makes one further claim which might in part be understood as a rebuttal to the attempt to extend either the argument from distress to animal lovers or the argument from the importance of character into a moral criticism of factory farming. This is the claim that to do so would be to increase our concern with animal welfare beyond its present level and that

the cost of increasing concern with animal welfare is to distract attention from the needs of those who certainly do have moral standing - namely, human beings. We live on a planet where millions of our fellow humans starve, or are near starving, and where many millions more are undernourished. In addition, the twin perils of pollution and exhaustion of natural resources threaten the futures of ourselves and our descendants. It is here that moral attention should be focused. Concern with animal welfare, while expressive of states of character that are admirable, is an irrelevance to be opposed rather than encouraged (p. 168). ${ }^{13}$

Carruthers acknowledges that one might object that it is always possible to be concerned with both animal and human welfare, but he protests that "in fact, much of the moral energy currently spent in defense of animals has been diverted from other domains." And this is surely something that could not please rational agents assessing our culture from behind a veil of ignorance.

Now it is tempting to respond to all of this, at least in the case of factory farming, by claiming that wellinformed rational agents would be likely to conclude that the inefficiency of factory farming is an important cause of the very problems of starvation, malnutrition, and exhaustion of natural resources, and so would choose to condemn it for that reason alone. And given that this is a fairly wide-spread view of the social costs of factory farming, it is somewhat disappointing that Carruthers does not address it. But there is a more general point to be made here than this: if it is the case that a great deal of valuable moral energy is currently being used to attack factory farming, this is surely because so many people do not presently believe that factory farming is morally objectionable. But the rational agents behind the veil of ignorance are trying precisely to decide which moral beliefs they think it would be best for everyone to have. If I have been successful in showing that the considerations Carruthers would have them give weight to would lead these agents to conclude that the best moral beliefs should include the belief that factory farming is objectionable, then no energy would be wasted opposing factory farming because everyone would agree that it is wrong. People do not currently devote their time to railing against the immorality of murder, after all, since its wrongness is generally recognized. Instead, they may worry about how it can best be prevented. But while it is difficult to determine how best to prevent crime or disease or overpopulation or other serious human problems, it is not difficult to determine how best to prevent factory farming. Rational agents would recognize this difference, and so would see no significant cost in terms of valuable moral energy in accepting a principle which condemned factory farming. ${ }^{14}$

\section{IV.}

I have argued thus far that if rational agents behind a veil of ignorance would have reason to accept Carruthers' arguments for embracing moral principles which place restrictions on their treatment of animals, then they would also have reason to accept principles which would extend moral protection to animals substantially beyond the level generally accorded them. If they agree to morally criticize individuals who harm animals for trivial reasons, then they will also agree to morally criticize social institutions and industries (and the people who support them) which harm animals for trivial social gains. I have used the case of factory farming as an example of this, since it is one which Carruthers explicitly concedes to produce only trivial benefits and claims to be morally unobjectionable, but if my arguments have been sound, then the same 
criterion would also be used to assess the use of animals for entertainment, sport, clothing, product testing, and so forth, as well as more "humane" methods of converting them into food. There is obviously room here for disagreement about which specific uses of animals such agents would ultimately accept and which they would reject, but I want now to assume that question has been satisfactorily resolved. Some cases of harming animals will be morally criticized and some will not, and some cases of harming humans will be morally criticized and some will not.

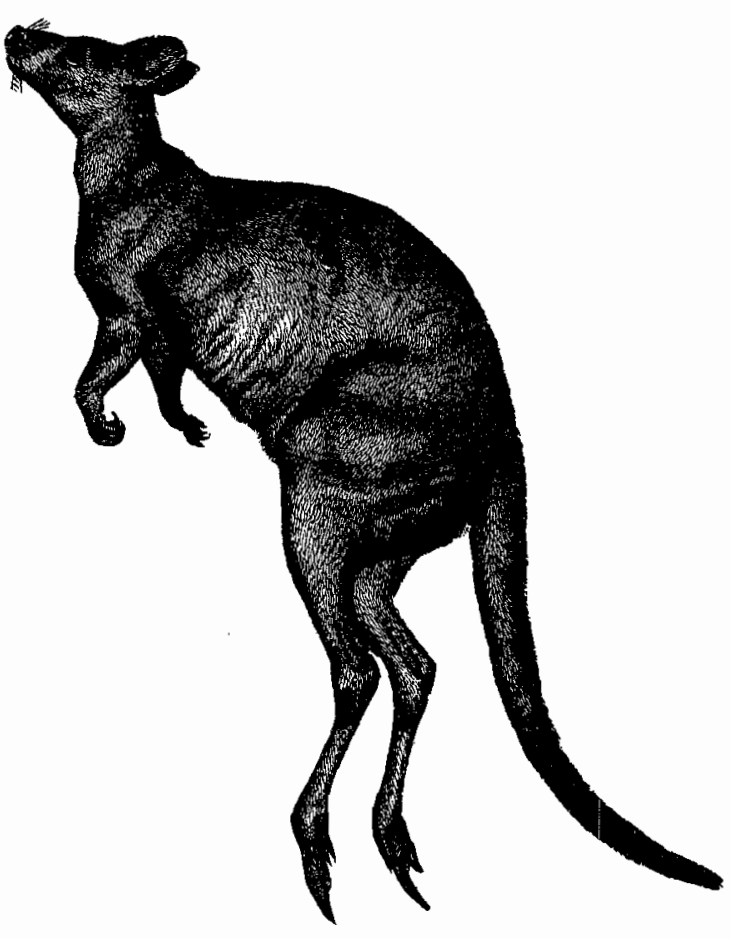

I want now to raise a question about the moral status which is accorded to animals by virtue of accepting these principles. Carruthers claims that moral contractarianism can justify according full moral standing to all humans while denying it to all animals, meaning that it can justify recognizing direct duties to all humans and only indirect ones to animals. On the face of $i t$, this should seem surprising since only rational agents can participate in the imagined deliberations and not all humans are rational agents. But Carruthers develops two arguments to show that humans who are not rational agents (e.g., infants, the severely retarded; for brevity, I will use the somewhat unattractive phrase "marginal humans") should nonetheless be accorded direct moral standing on the contractarian picture of morality. I want to argue that if this is so, then so should animals.

Carruthers' main argument for according moral standing to marginal humans ${ }^{15}$ is a version of the slippery slope argument. Contracting agents behind the veil of ignorance might initially be tempted to agree to principles which would attach moral standing only to rational agents while withholding it from marginal humans. Such agents are rational, after all, and so know that they will not themselves be marginal humans, and they therefore have no obvious reason to accord such humans direct moral standing. But Carruthers argues that in choosing moral principles, such agents must not only consider what the principles themselves say, but must also "pay attention to the ways in which those principles might be distorted or abused" (p. 115). In particular, the contracting agents will know that while there is a clear and easily-applied distinction between humans and nonhumans, there is no such sharp boundary between a human who barely qualifies as a rational agent and a human who barely doesn't. Moral principles which accord direct standing to agents but not to marginal humans, then, "would be inherently susceptible to abuse by unscrupulous people" in a way that principles which accorded standing to humans but not to nonhumans would not (p. 115). Principles which relied on tenuous distinctions between human agents and human patients could too readily be used, for example, to convince people to deny rights to those who are perceived to be sexually deviant, or merely intellectually inferior, while principles which relied on the clear and absolute distinction between humans and nonhumans could not. To accept moral principles which exclude marginal humans from direct standing, these contracting agents would therefore conclude, would be to agree to put themselves in a position from which a slippery slope would easily lead to "all kinds of barbarisms against those who are rational agents" (p. 114).

Now one might think that the most an argument of this sort could establish would be that rational agents would agree to treat marginal humans as if they had direct moral standing. They are convinced to accept the theory which accords direct standing to marginal humans, that is, not because they think that it is the best theory to govern their interaction, but because they worry that the theory that really is best (the one which attributes direct standing only to agents) is too likely to 
be abused in the real world. They accord direct standing to marginal humans, then, not because they believe that marginal humans really merit such standing, but because they believe that it is convenient to accord such standing to them. But Carruthers denies that, from the contractarian point of view, there can be such a distinction between saying that a being really merits moral standing and saying that it is convenient to accord it such standing (see pp. 116-17). Legitimate moral principles just are those which rational agents choosing from behind a veil of ignorance would accept. The slippery slope argument shows that they would have reason to accept principles on which all humans have direct moral standing. So, on the contractarian account, all humans do have direct moral standing.

Once again, I am not concerned to question the merits of Carruthers' argument. But if it is accepted, there is no clear reason why it should not be extended to show that animals, too, have direct moral standing. I do not mean by this that a suitably revised slippery slope argument would make the contracting agents fear that a theory which denied moral standing to animals would be abused to deny standing to them as well. This does not seem plausible. Rather, I have in mind Carruthers' claim that to show that marginal humans have direct standing one must merely show that the contracting agents would have some reason to want people to accept a moral theory which made such a claim. For it seems that the direct moral standing of animals could be established using precisely the same strategy, and from considerations which Carruthers has himself already endorsed.

Carruthers has argued, remember, that rational agents will have reason to endorse the inculcation of a sympathetic disposition toward animals in which the actions of people who have the right sort of character "are undertaken for the sake of the animals in question." The contracting agents endorse the merits of such a disposition because of its beneficial effects for other people, it is true, but the disposition which they thereby endorse nonetheless views animals as mattering for their own sakes: "For this is what having the right kind of sympathetic virtue consists in" (p. 154). Following our discussion of marginal humans, then, we might initially be tempted to say that rational agents would agree to a set of moral principles on which when it is wrong to harm an animal it is wrong because the animal has moral standing, not because the rational agents believe that animals merit such standing, but because they believe that it will be beneficial to humans to act on the convenient belief that animals have such standing. But, if we accept Carruther's argument in the case of marginal humans, we must conclude that to say that rational agents would agree to principles which praise those who view animals as having moral standing is simply to say that rational agents would agree to accord animals such standing, which is to say that on the contractarian account animals have such standing.

Carruthers acknowledges that the person with the sort of character which the rational agents will recommend will be likely to think "that animal suffering has moral standing, mattering for its own sake. For those who have the right moral dispositions in this area will act for the sake of the animal when prompted by feelings of sympathy" (p. 157). But he insists that this would be an "illusion" resulting from a failure to recognize that

there may be a variety of different levels to moral thinking. On the one hand there is the level of thought that manifests our settled moral dispositions and attitudes (this is where sympathy for animal suffering belongs), but on the other hand there is the level of theoretical reflection upon those dispositions and attitudes, asking how they may be justified by an acceptable moral theory. It is at this level that we come to realise, as contractualists, that animals are without moral standing (p. 157).

But if this distinction justifies thinking of the moral standing of animals as merely an "illusion" which it is useful to cause people to fall into at the level of thought that manifests their settled moral attitudes, then it must equally justify thinking of the moral standing of marginal humans as an illusion which it is useful to agree to have people accept at the same level. At the level of the moral beliefs which the contractarian thinks that people ought to have, after all, marginal humans are a matter of direct concem, but at the level of theoretical reflection, the contractarian teaches that such beliefs are justified solely on the grounds that they benefit other rational agents, who seen from this perspective are the only ones who are of direct concern.

I am not concerned here to insist that we must therefore characterize animals as having direct moral standing on the contractarian account. We might just as naturally say that both they and marginal humans are only of indirect concern, although in both cases rational 
agents agree that people have reason to see them as objects of direct concern. The point is simply that the two cases should stand or fall together, so that in either case, Carruthers has failed to provide a significant sense in which all humans do, and all animals do not, have "full" moral standing.

\section{V.}

I have, throughout this paper, resisted commenting on the merits of Carruthers' arguments for recognizing minimal restrictions on our treatment of animals, and I will resist again in conclusion. For the point of this paper has not been that those who seek to extend the moral protection of animals beyond the levels presently accorded them should abandon their commitment to consequentialist or deontological moral theories and instead embrace contractarianism as the inost effective way to further their cause. There may well prove to be good reasons to reject contractarianism as a moral theory. The point has rather been that there are people who seek to deny further moral protection to animals without lapsing into the unacceptable view that we have no moral duties regarding animals at all, and that Carruthers presents contractarianism as a view that furthers their cause. But this contractarian gambit, as he develops it, ultimately runs aground on a dilemma: either Carruthers' arguments for generating minimal duties regarding animals fail, in which case the contractarian theory must be rejected as unacceptably counterintuitive, or his arguments succeed, in which case they also generate moral judgments about our treatment of animals which go substantially beyond those presently accepted, both in terms of their content and in terms of the moral status they accord to animals. ${ }^{16}$

\section{Notes}

${ }^{1}$ Peter Carruthers, The Animals Issue: Moral theory in practice (Cambridge: Cambridge University Press, 1992), pp. 194, xii, 169. Parenthetical references in the text are to page numbers in this book. I follow Carruthers here in using the term "animal" to refer to nonhuman animals. It is worth noting that Carruthers is not the first to present moral contractualism as a way of resisting such an extension of moral protection to animals. His project is essentially the same as the one Jan Narveson has pursued in a series of papers, although Narveson is not mentioned in Carruthers' book (see, e.g., Narveson, "Animal Rights," Canadian Joumal of Philosoplyy Vol. 7, No. 1 (March 1977); "Animal Rights Revisited," in H. Miller and W. Williams, eds., Ethics and Animals (Clifton, NJ:
Humana Press, 1983); "On a Case for Animal Rights," The Monist Vol. 70, No. 1 (January 1987)).

2 I use the terms "contractarianism" and "contractualism" interchangeably.

${ }^{3}$ It is worth noting that Rawls himself resists the claim that the contractarian model can be used to underwrite a complete theory of morality. Even if it is extended beyond justice to all of the social virtues, he acknowledges, "it would seem to include only our relations with other persons and to leave out of account how we are to conduct ourselves toward animals and the rest of nature. I do not contend that the contract notion offers a way to approach these questions which are certainly of the first importance" (Rawls, A Theory of Justice (Cambridge: Harvard University Press, 1971), p. 17). It is also worth noting that some have questioned whether the contractors behind the veil of ignorance should be permitted to know what species they will belong to (see, e.g., Tom Regan, The Case for Animal Rights (Berkeley: University of California Press, 1983), pp. 171-72. Carruthers offers a reply to this concern at pp. 101-103).

${ }^{4}$ Impartiality is ensured by the fact that choices and objections must be rational and by the stipulation that each must share the aim of reaching free and unforced agreement with others (p. 39).

${ }^{5}$ Strictly speaking, there is a third argument grounded in the likelihood that such agents would accept rules of private property and would thus accept rules which would prevent one person from harming animals which belonged to another. But even Carruthers concedes that "an appeal to property rights cannot take us very far in attempting to reconcile contractualism with commonsense attitudes," (p. 106) so I will pass over it without further comment.

${ }^{6}$ Carruthers does not explicitly frame his argument in terms of appeal to a best worst-case standard, and it might plausibly be argued that such agents would instead appeal to a utilitarian standard of maximizing the overall level of preference satisfaction. But Carruthers is concerned to defend contractarianism as an alternative to such utilitarian standards, and I take it that my construal of his position in terms of agents avoiding the worst-case outcome is the most plausible way of understanding his attempt to do so.

${ }^{7}$ One might object that the benefits to some are substantial, namely those who own stock in the companies who run the factory farms. But this is misleading: if meat production were morally prohibited, such people would simply invest their money elsewhere. No one reasoning from behind the veil of ignorance would have reason to suppose that he would make more money in a market that included factory farming than in one that did not, so no one will think there is a cost to him in condemning such farming that is comparable to the cost to the animal lover of permitting it. 
${ }^{8}$ It might be objected that this argument would prove ineffective against factory farming carried out in secret. Since no animal lovers would be made aware of the suffering caused to the animals, none would be caused any distress. Some versions of contractarianism could block this move directly by appealing to a publicity condition which would rule out such secrecy, but it is not clear that such a response is available on Carruthers' account. So it may be in principle possible that the rational contractors would agree that factory farming was permissible as long as it was carried out in secret. It seems more likely, though, that such agents would be deterred from this by the potentially great costs of permitting such corporate secrecy (as discussed in section IV below, Carruthers maintains that the contracting agents must take into account not only what the rules they consider permit, but how readily they might be abused). They would therefore insist on the availability of public inspection of farms, and thus while their moral principles might admit the truth of the claim "if farming practices could permissibly be kept secret, then secret factory farming would be morally permissible," they would at the same time render the antecedent of the claim false. And if it is not permissible to keep farming practices secret, then it is not permissible to engage in factory farming in secret.

${ }^{9}$ As Carruthers notes (pp. 157-58), this is the sort of argument defended by Kant (in "Duties to Animals and Spirits," in his Lectures on Ethics) and it goes back to medieval scholastics such as Aquinas (e.g., Summa Contra Gentiles, Book III, Part II, Chap. CXII) if not further; as Keith Thomas has pointed out, the "ancient Athenians were said [by the scholastics] to have condemned a child who blinded crows because they thought that one day he would be cruel to men" (Thomas, Man and the Natural World: A History of the Modern Sensibility (New York: Pantheon Books, 1983), p. 150; the relevant passages from Kant and Aquinas are both reprinted in Tom Regan and Peter Singer, eds., Animal Rights and Human Obligations, 2nd ed. (Englewood Cliffs, NJ: Prentice Hall, 1989)).

${ }^{10}$ This objection might be taken as merely one illustration of a more general problem with Carruthers' argument. Carruthers' argument rests on the general claim that whenever a person is earning a living, that person is acting from nontrivial motives. But we can imagine any number of trivial motives a person might have for choosing one means of earning a living over another. A person may go to work for a certain company, for example, because he has a preference for working for companies which advertise on even-numbered pages in the phone book, but surely the fact that he makes a living working for the company does not show that his motive for doing so is not a trivial one.

${ }^{11}$ This supposition seems supported by the extremely high turnover rate for such positions.
${ }^{12}$ It might be suggested that this argument assumes that the consumer is aware, at least at a general level, of the suffering which animals must endure under such circumstances, and that it would therefore provide no basis for criticizing the consumer of factory-farmed meat who is blissfully ignorant of these conditions. This raises the potentially thorny problem of what a moral contractarian should say about the question of culpable ignorance, and I cannot explore that issue in any detail here. It does seem plausible, though, to suggest that our imagined contracting agents would denounce the sort of person who makes no effort at all to learn about conditions in the industries he supports with his wallet (lest he inadvertently contribute to the survival of a company which employs slave labor, for example). And so if I am right to suggest that the contractarian would insist on forbidding corporate secrecy (see footnote 8 above), then he may well be left agreeing with the claim that "if a factory-farm consumer's ignorance of the farm's conditions reveals no defect of character, then his purchasing of factory-farmed meat reveals no defect of character," while maintaining that there are good reasons to deny the truth of the claim's antecedent. So the consumer will, on this account, be legitimately accused of indifference to the suffering of animals, either because he knowingly contributes to it for such trivial benefits, or because he cares too little about it to obtain even the most generally accessible information about it.

${ }^{13}$ Carruthers has harsher words in his preface: "I regard the present popular concern with animal rights in our culture as a reflection of moral decadence" (xi).

${ }^{14}$ It is possible, of course, that in launching this objection Carruthers should be understood as stepping outside of his contractarian framework, that his complaint is not that contracting agents would fear a waste of moral energy if they accept greater moral restrictions on the treatment of animals but, rather, that in the world as things presently stand, I will waste valuable moral energy if I lobby on behalf of the welfare of animals. But if this is what Carruthers means, then his observation does nothing to overturn my suggestion that contracting agents would accept such restrictions and would instead, if accepted, seem to show only that I have some reason not to model my moral agenda after the decisions that would be made by rational agents behind a veil of ignorance.

15 Carruthers presents a second argument from the desirability of social stability (pp. 117-18), but my response is directed at the strategy which is used in both arguments, so I will not treat that one separately.

${ }^{16}$ I would like to thank David DeGrazia, Dale Jamieson, Harlan B. Miller, Jon Mandle, Alec Walen and Sara Worley for their useful comments on an earlier version of this paper. 